The Compleat Naturalist by Wilfrid Blunt. Collins, £3.50.

Carl Linnaeus is a rather unusual figure in the history of science. He did not perhaps contribute very much to our understanding of the processes of the natural world, his system of classification has long since been forgotten, and indeed his most important contribution, the introduction of binomial nomenclature, was achieved almost by accident. And yet by his immense energy in classifying and naming over 7,000 plants alone, he made possible the massive efforts of the 19th century in classification, and thus the scientific study of nature.

Linnaeus must also be one of the best served figures in the history of science for biography. This latest, and beautifully produced book is a most readable account of his life, giving an excellent picture of the society and climate of thought in which he worked. Written with a dry sense of humour most appropriate to the sometimes absurd reactions that Linnaeus' theories sometimes provoked, the book produces a frank, but always tolerant view of a man who was so aware of his own place in history that he left instructions for a plaque to be erected after his death, bearing the words Princeps Botanicorum.

Mr Blunt merges narrative and portrait well and many of the anecdotes are delightful. Because the local parson was long-winded, Linnaeus, who always took his dog to church, would leave after an hour. When he was too ill to attend, the dog occupied the family pew alone, but from habit would leave on the hour. The illustrations are sumptuous, many of the plates being of contemporary botanical illustrations, which are quite beautiful and would almost justify the purchase on their own.

However the book does not seriously attempt to encompass Linnaeus's intellectual development, this being covered in an excellent appendix by William Stearn. The botanist may find this disjunction unfortunate, for it fails to set Linnaeus's scientific thought in the otherwise admirable context Mr Blunt has created. Despite this, I would warmly recommend this book as a delightful way to become acquainted with a most remarkable man.

ALASTAIR FITTER

\title{
The Natural History of the African Elephant, by Sylvia K. Sikes. Weidenfeld and Nicolson, $£ 10$.
}

This expensive book was written, according to the jacket blurb, to meet the need for an up-to-date handbook on a species which is currently at the centre of much conservation controversy in East Africa. The text, illustrated by an interesting and adequate selection of photographs and line drawings, is divided into three. The first part, comprising seven chapters, consists of a comprehensive review of the literature concerning the functional anatomy, histology, physiology and pathology of the African elephant, the last chapter containing a description of the author's own researches into the correlation between vascular disease and environmental conditions. Part Two gives an account of the interaction of the animal with its environment and a description of its behaviour and community structure. In Part Three a useful historical survey is presented of man's past and present exploitation of the species in Africa, together with an account of some of the problems encountered today in those East African national parks which are considered to have an overpopulation of elephants.

The author's style is lucid and easy to read, and her aim, to provide a reference work on the African elephant, has been largely achieved, but 
one cannot help wondering why she has not discussed in the text (although giving some of the references in the bibliography) the recent exhaustive work by Laws on the population dy namics of the elephants in the national parks of Kenya and Uganda.

Perhaps the least satisfactory chapter is the last, on conservation. One might have hoped that Dr Sikes would have had some constructive suggestions for the solution of the enormous problem of elephant over-population which faces some East African parks today. It is all very well to suggest as she does that an annual, sustained-yield crop should be taken from the elephant stocks, but what of the present over-populations? No suggestions on how to deal with these are given. It is no use bemoaning the fact that no scientists were appointed to monitor the growth of the large mammal numbers at the time the parks were created and then sniping at the 'foreign scientists' financed by 'foreign investors' (sic) who are now working in the parks and trying desperately to make up for the time which has been lost. To suggest, as Dr Sikes does, that there is something sinister in this and that these scientists 'know little of the (country's) heritage and care less' is plainly ridiculous. In fact, research units in the parks of Kenya, Uganda and Tanzania receive funds from a variety of sources including the national universities and the national governments. Similarly the European, American and African staff of the research units are dedicated people, well aware of the shortcomings of previous policies in the formation of which they played no part. These people, too, are conscious of the urgency of the problems and if they 'suddenly' produce management proposals it is because only now are the results of their research becoming available.

However, apart from this rather querulous last chapter, the book contains a useful compilation and discussion of the available references to the African elephant in the scientific literature, and, in spite of its high cost, it will be constantly consulted by students of the species.

MICHAEL WOODFORD

\section{East African Mammals, by Jonathon Kingdon. Academic Press, $£ 12.00$}

East Africa is popularly the part of the world most associated with wildlife, especially mammals. Nevertheless, it has been surprisingly difficult to get a balanced picture of the mammal zoology. No modern book deals in depth with them all. Jonathon Kingdon has produced the first of three volumes which will do just this, telling us about the morphology, ecology and behaviour of all the mammal species he recognises as living in the area. Further, he has done this in an unusual way. There are no photographs; instead he has used his own drawings, some in colour, to illustrate not only the outward appearance and postures of the animals but also their muscular and skeletal structures.

Volume I opens with a short account of his method, followed by three chapters on the environment, topography, climate, vegetation, geology and evolutionary trends, with two 'appendices', one on the Bwamba Forest and the other on mammal anatomy. The next 300 pages cover the general zoology of the primates, hyraxes, pangolins, aardvark and dugong - this part would have been more helpful divided into chapters - and the volume ends with a list of families, a gazeteer, and a most comprehensive and useful bibliography.

While the text, taking the reader easily through the species and highlighting with well chosen local anecdote, is good, to many people the import of the book will be in its illustrations. The standard of his 